\title{
Efficacy and safety of fentanyl buccal for cancer pain management by administration through a soluble film: an update
}

This article was published in the following Dove Press journal:

Cancer Management and Research

23 November 2010

Number of times this article has been viewed

\section{Marvin Omar Delgado-Guay}

Division of Geriatrics and Palliative Medicine, The University of Texas, Medical School at Houston, Houston, TX, USA
Correspondence: Marvin Omar Delgado Guay

Division of Geriatrics and Palliative

Medicine, The University of Texas,

Medical School at Houston, Lyndon B

Johnson General Hospital 5656

Kelley St., Houston TX 77026, USA

$\mathrm{Tel}+\mathrm{I} 7135664794$

Fax + I 713 5664850

Email marvin.o.delgadoguay@uth.tmc.edu

\begin{abstract}
More than half of patients receiving prescription medicine for cancer pain have been reported to experience inadequate pain relief or breakthrough pain. Buccal administration can deliver lipophilic opioids rapidly to the systemic circulation through the buccal mucosa, limiting gastrointestinal motility and first-pass metabolism. This review updates the safety and efficacy of fentanyl buccal soluble film (FBSF) in patients with cancer pain. Literature was identified through searches of Medline (PubMed). Search terms included combinations of the following: cancer pain, fentanyl, fentanyl buccal soluble film, pharmacology, kinetics, safety, efficacy and toxicity. FBSF is an oral transmucosal form of fentanyl citrate developed as a treatment of breakthrough pain in opioid-tolerant patients with cancer. Studies have shown that it is well tolerated in the oral cavity, with adequate bioavailability and safety in cancer patients. Further studies are warranted to evaluate, in comparison with other short-acting opioids, its efficacy in the management of breakthrough cancer pain, its addictive potential and its economic impact in cancer patients.
\end{abstract}

Keywords: fentanyl buccal soluble film, cancer pain

\section{Introduction}

Pain is a common symptom in cancer patients. ${ }^{1,2}$ It may be poorly controlled because it is underreported or patients may have problems with communication or cognition, and physicians may undertreat it due to both inherent biases and concerns about use of medications in cancer patients due to the presence of comorbid diseases, and increased risk of adverse drug reactions. ${ }^{3-6}$ Cancer pain management is truly a public health and quality-of-care issue. Pain in cancer patients is not yet treated effectively. ${ }^{1-4,7,8}$

Pain related to cancer is often characterized by two components: first, persistent pain, for which the treatment is long-acting opioid products; second, "breakthrough pain". Breakthrough pain is defined as "the transient exacerbation of pain occurring in a patient with otherwise controlled persistent pain", ${ }^{2}$ and is a common and distressful symptom. It has been reported in $64.8 \%$ of patients with cancer pain. ${ }^{9}$ Breakthrough pain was associated with higher pain scores and functional impairment. ${ }^{9}$

Cancer patients who experience pain with multiple distressing symptoms benefit from an interdisciplinary evaluation and management of these symptoms with the goal of maximizing their quality of life. Breakthrough pain episodes are treated with oral short-acting opioids such as hydromorphone, morphine, and oxycodone. ${ }^{2,10}$ Patients with cancer might experience inadequate pain relief most of the time. Breivik et al observed that $58 \%$ of cancer patients with breakthrough pain reported inadequate pain relief at all times. ${ }^{11}$ Consequently, the "ultrarapid"-acting opioids are indicated for this 
type of pain. Specifically, with the transmucosal formulation of fentanyl the absorption through the oral mucosa from either the buccal cavity or sublingually is more rapid than oral absorption. ${ }^{2}$ Other benefits of oral transmucosal delivery include better tolerance in patients with dysphagia, nausea or vomiting, ${ }^{12}$ and minimization of first-pass metabolism. ${ }^{2,12}$ Fentanyl is a potent opioid analgesic that is well absorbed via the oral mucosa. ${ }^{12-14}$ Various formulations are approved by regulatory authorities. The most recent product approved by the US Food and Drug Administration is fentanyl buccal soluble film (FBSF). This review provides the clinician with an update on the current role of FBSF, and its efficacy and safety in the management of cancer patients with pain.

\section{Method}

Literature was identified through searches of Medline (PubMed). A bibliographical review of articles identified by these searches was also performed. Search terms included combinations of the following: cancer pain, fentanyl, fentanyl buccal soluble film, pharmacology, kinetics, and toxicity. All clinical trials, retrospective studies, and case reports relevant to FBSF and published in English were identified. Each was reviewed for data on the clinical pharmacology and safety of FBSF administration. Data from these studies and information from review articles and pharmaceutical prescribing information were included in this review.

\section{Fentanyl}

Fentanyl is a mu-opioid receptor agonist, which acts as a pure agonist. ${ }^{13}$ It is a highly lipophilic compound that is freely soluble in organic solvents and sparingly soluble in water. ${ }^{15}$ In its structure, fentanyl has a piperidine ring which plays an important role in its efficacy. The piperidine ring facilitates docking with the mu-opioid receptor. ${ }^{16}$ The association with the mu-opioid receptor is rapid $\left(\mathrm{t}_{1 / 2}: 2.5\right.$ minutes $)$. Fentanyl is more potent than morphine as evidenced by its $\mathrm{Ki}$ of $2.9 \pm 0.2$ vs morphine's Ki of $15 .{ }^{13}$ It has been described that fentanyl can interact with serotonin receptors as evidenced by its decreased analgesic effect when combined with $5-\mathrm{HT}_{1 \mathrm{~A}}$ receptor antagonists. ${ }^{17}$ Fentanyl has high protein-binding ability and low water solubility. It has a high volume of distribution and a high molecular weight, and thus is not dialyzable. ${ }^{18}$ Fentanyl is mainly metabolized by N-dealkylation to norfentanyl (4-N-[N-propionylanilino] piperidine) and hydroxyfentanyl, which are present in plasma and urine. ${ }^{19}$ There is minimal fecal excretion and it is mostly excreted by the kidneys. ${ }^{18,19}$ Cytochrome P450 isoforms, found in the small bowel, can produce first-pass metabolism of fentanyl when administered by the oral route. ${ }^{19}$ The activity of cytochrome $\mathrm{P} 450$ 3A4, the main isoform responsible for $\mathrm{N}$-dealkylation of fentanyl, ${ }^{19}$ is inhibited by macrolides, antifungal agents, antidepressants (sertraline, fluoxetine, fluvoxamine), oral contraceptives, omeprazole, antiviral agents, valproic acid and cimetidine. When fentanyl is combined with these medications, the duration of the effect is prolonged and elimination slowed. In contrast, antiretroviral medications and rifampin induce cytochrome P450 3A4 activity, reducing the analgesic effect of fentanyl. ${ }^{20,21}$ Fentanyl is compatible with dexamethasone, hyoscine butylbromide, levopromazine, haloperidol, ondansetron and midazolam. ${ }^{13}$

Fentanyl can be administered transdermally, intravenously, subcutaneously, transmucosally, and sublingually. ${ }^{13,14}$ Several fentanyl formulations are approved. Oral transmucosal fentanyl citrate (OTFC) is a buccal formulation that is composed of a fentanyl lozenge on a stick that requires the patient to continuously roll a lollipop in the inner portion of their cheek. This form of administration and the formulation's high sugar content can provide a suboptimal therapy for some patients. ${ }^{2}$ Another buccal formulation is fentanyl buccal tablet (FBT), which has been approved in United States and Europe. This formulation acts through an effervescence reaction that enhances fentanyl absorption through the buccal mucosa. This effervescent buccal tablet can be absorbed twice as fast as when the drug is swallowed or as the fentanyl lollipop..$^{22-26}$ The most recent formulation of fentanyl that has been approved for the treatment of breakthrough pain in cancer patients is FBSF.

\section{Fentanyl buccal soluble film}

FBSF is an oral transmucosal form of fentanyl citrate. It has a BioErodible MucoAdhesive (BEMA ${ }^{\circledR}$; BioDelivery Sciences, Inc., Raleigh, NC) delivery technology. ${ }^{14,27-29}$ This technology consists of two different layers made of water-soluble polymeric films, one bioadhesive layer and one inactive layer. The bioadhesive layer contains fentanyl citrate that adheres within seconds of making contact with the moist buccal mucosa. The inactive layer isolates the bioadhesive layer from the buccal cavity, minimizing the amount of fentanyl that is swallowed and facilitating delivery directly to the buccal mucosa. ${ }^{27-29}$ Once applied FBSF starts to dissolve in minutes and is completely dissolved within 15 to 30 minutes without patient effort. It requires a minimal quantity of saliva. Delivered by this system, the proportion of the fentanyl dose that undergoes transmucosal absorption is approximately 50\% and the absolute bioavailability is approximately $71 \%{ }^{29-31}$ (Table 1). In a randomized, open-label trial, 12 healthy subjects received 
Table I Pharmacology of fentanyl buccal soluble film (FBSF)

\begin{tabular}{ll}
\hline & Characteristics \\
\hline Class & Potent opioid analgesic \\
Route & Oral transmucosal (buccal) \\
& BioErodible MucoAdhesive Delivery Technology \\
Bioavailability & $71 \%$ \\
Protein binding & $80 \%-85 \%$ \\
Metabolism & Hepatic and intestinal (cytochrome P450 3A4) \\
Half-life & 14 hours \\
Elimination & Urine (mainly) \\
Strengths & $200,400,600,800,1200 \mu \mathrm{g}$ \\
\hline
\end{tabular}

single doses of three FBSF formulations ( $\mathrm{pH} 6, \mathrm{pH} 7.25$, and $\mathrm{pH} 8.5$ ) and OTFC, with concurrent naltrexone. The study demonstrated that, of these three formulations, the $\mathrm{pH} 7.25$ FBSF formulation reached peak plasma fentanyl concentration $\left(\mathrm{C}_{\max }\right)$ fastest and had the highest $\mathrm{C}_{\max }$ value and the greatest area under the curve concentration. Compared with OTFC, peak plasma fentanyl concentrations with $\mathrm{pH} 7.25 \mathrm{FBSF}$ were significantly higher $\left(\right.$ mean $\mathrm{C}_{\max } 1.67 \mathrm{vs} 1.03 \mathrm{ng} / \mathrm{mL}$ ) ${ }^{28}$ There is a direct relationship between the surface area of the dose unit and the dose of fentanyl combined with the mucosa contact time that results in consistent plasma concentrations when equivalent doses are delivered by single or multiple dosage units. ${ }^{30}$ Consequently, the absorption surface area with a single $800-\mu \mathrm{g}$ dose is exactly the same as with four individual $200-\mu \mathrm{g}$ films..$^{29}$ Rauck et al in a multicenter, randomized, double-blind placebo-controlled, multiple-crossover study, with opioidtolerant adult patients with chronic cancer pain experiencing one to four daily episodes of breakthrough pain, showed that FBSF is an effective option for control of breakthrough pain in patients receiving ongoing opioid therapy. ${ }^{14}$ This efficacy was evidenced by a greater number of the sum of pain intensity difference at 30 minutes postdose FBSF than placebo. FBSF was well tolerated in the oral cavity, with no treatment-related oral adverse effects. ${ }^{14}$ At this time no other study has compared the efficacy of FBSF against other short-acting opioids in cancer patients with pain.

The recommended starting dose of FBSF, regardless of prior therapy, is $200 \mu \mathrm{g}$ per episode. The dose can be increased by $200 \mu \mathrm{g}$ using $200-\mu \mathrm{g}$ films in different areas of the mouth. If the pain persists after a $800-\mu \mathrm{g}$ dose, a single $1200-\mu \mathrm{g}$ film could be prescribed for the next episode. ${ }^{31}$ Single doses should be separated by at least 2 hours. It has been recommended that no more than four doses should be given per day. Doses higher than $1200 \mu \mathrm{g}$ per episode are not recommended. ${ }^{31}$

Adverse events with FBSF are mainly gastrointestinal (nausea, vomiting, constipation) and central nervous system disorders (dizziness, headaches). No changes have been reported in vital signs, electrocardiograms, physical examinations, or clinical laboratory tests..$^{28}$ It is classified as category $\mathrm{C}$ (risk cannot be ruled out) for use during pregnancy. ${ }^{31}$

\section{Conclusion}

FBSF is an effective option for control of breakthrough pain in cancer patients receiving ongoing opioid therapy. It has adequate bioavailability and tolerability. Further studies are warranted to evaluate, in comparison with other short-acting opioids, its efficacy in the management of breakthrough cancer pain, its addictive potential and its economic impact in cancer patients.

\section{Disclosure}

The author discloses no conflicts of interest.

\section{References}

1. Delgado-Guay MO, Bruera E. Management of pain in the older person with cancer. Part 1. Oncology. 2008;22:56-61.

2. de Leon-Casasola OA. Current developments in opioid therapy for management of cancer pain. Clin J Pain. 2008;24:S3-S7.

3. Yennurajalingam S, Braiteh F, Bruera E. Pain and terminal delirium research in the elderly. Clin Geriatr Med. 2005;21:93-119.

4. Basso U, Monfardinin S. Multidimensional geriatric evaluation in elderly cancer patients: a practical approach. Eur J Cancer Care. 2004; 13:424-433.

5. Mercadante S, Arcuri E. Pharmacological management of cancer pain in the elderly. Drugs Aging. 2007;24:761-776.

6. Dalal S, Del Fabbro E, Bruera E. Symptom control in palliative care part 1: oncology as a paradigmatic example. $J$ Palliat Med. 2006;9: 391-408.

7. Aziz NM. Cancer survivorship research: state of knowledge, challenges and opportunities. Acta Oncol. 2007;46:417-443.

8. World Health Organization (WHO). Cancer Pain Relief and Palliative Care. Geneva, Switzerland: WHO, 1990:804.

9. Caraceni A, Martini C, Zecca E, et al. Breakthrough pain characteristics and syndromes in patients with cancer pain. An international survey. Palliat Med. 2004;18:177-183.

10. William L, Macleod R. Management of breakthrough pain in patients with cancer. Drugs. 2008;68:913-924.

11. Breivik H, Cherny N, Collett B, et al. Cancer-related pain: a pan-European survey of prevalence, treatment, and patient attitudes. Ann Oncol. 2009;20:1420-1433.

12. Zhang H, Zhang J, Streisand JB. Oral mucosal drug delivery: clinical pharmacokinetics and therapeutic applications. Clin Pharmacokinet. 2002;41:661-680.

13. Prommer E. The role of Fentanyl in cancer-related pain. J Palliat Med. 2009;12:947-954.

14. Rauck R, North J, Gever LN, Tagarro I, Finn AL. Fentanyl buccal soluble film (FBSF) for breakthrough pain patients with cancer: a randomized, double-blind, placebo-controlled study. Ann Oncol. 2010; 21:1308-1314.

15. Ummenhofer WC, Arends RH, Shen DD, Bernards CM. Comparative spinal distribution and clearance kinetics of intrathecal administered morphine, fentanyl, alfentanil, and sufentanyl. Anesthesiology. 2000; 92:739-753.

16. Dosen-Micovic L, Ivanovic M, Micovic V. Steric interactions and the activity of fentanyl analogs at the [mu]-opioid receptor. Bioorg Med Chem. 2006;14:2887-2895. 
17. Clarke RW, Ward RE. The role of 5-HT(1A)-receptors in fentanyl-induced bulbospinal inhibition of a spinal withdrawal reflex in the rabbit. Pain. 2000;85:239-245.

18. Dean M. Opioids in renal failure and dialysis patients. J Pain Symptom Manage. 2004;28:497-504.

19. Murtagh FE, Chai MO, Donohoe P, Edmonds PM, Higginson IJ. The use of opioid analgesia in end-stage renal disease patients managed without dialysis: recommendations for practice. J Pain Palliat Care Pharmacother. 2007;21:5-16.

20. Olkkola KT, Palkama VJ, Neuvonen PJ. Ritonavir's role in reducing fentanyl clearance and prolonging its half-life. Anesthesiology. 1999;91:681-685.

21. Takane H, Nosaka A, Wakushima $\mathrm{H}$, et al. Rifampin reduces the analgesic effect of transdermal fentanyl. Ann Pharmacother. 2005;39: 2139-2140.

22. Webster LR. Fentanyl buccal tablets. Expert Opin Investig Drugs. 2006; 15:1469-1473.

23. Darwish M, Tempero K, Kirby M, Thompson J. Pharmacokinetic and dose proportionality of fentanyl effervescent buccal tablets in healthy volunteers. Clin Pharmacokinet. 2005;44:1279-1286.

24. Grape S, Schug SA, Lauer S, Schug BS. Formulations of fentanyl for the management of pain. Drugs. 2010;70:57-72.
25. Weinstein SM, Messina J, Xie F. Fentanyl buccal tablet for the treatment of breakthrough pain in opioid-tolerant patients with chronic cancer pain. Cancer. 2009;115:2571-2579.

26. Zeppetella G, Messina J, Xie F, Slatkin NE. Consistent and clinically relevant effects with fentanyl buccal tablet in the treatment of patients receiving maintenance opioid therapy and experiencing cancer-related breakthrough pain. Pain Practice. 2010;10:287-293.

27. Vasisht N, Gever LN, Tagarro I, Finn AL. Evaluation of the singleand multiple-dose pharmacokinetics of fentanyl buccal soluble film in normal healthy volunteers. J Clin Pharmacol. 2010;50:785-791.

28. Vasisht N, Gever LN, Tagarro I, Finn AL. Formulation selection and pharmacokinetic comparison of fentanyl buccal soluble film with oral transmucosal fentanyl citrate. Clin Drug Investig. 2009;29: 647-654.

29. Vasisht N, Gever LN, Tagarro I, Finn AL. Single-dose pharmacokinetics of fentanyl buccal soluble film. Pain Med. 2010;11:1017-1023.

30. Vasisht N, Stark J, Finn A. BEMA fentanyl shows a favorable pharmacokinetic profile and dose linearity in healthy volunteers. Reg Anesth Pain Med. 2008;32:8 2008 Annual General Meeting of the American Society of Anesthesiologists, October 17, 2008, Orlando FL.

31. Fentanyl buccal soluble film (Onsolis) for breakthrough cancer pain. The Medical Letter. 2010;52:30-31.

\section{Publish your work in this journal}

Cancer Management and Research is an international, peer-reviewed open access journal focusing on cancer research and the optimal use of preventative and integrated treatment interventions to achieve improved outcomes, enhanced survival and quality of life for the cancer patient. The journal welcomes original research, clinical \& epidemiological

\section{Dovepress}

studies, reviews \& evaluations, guidelines, expert opinion \& commentary, case reports \& extended reports. The manuscript management system is completely online and includes a very quick and fair peerreview system, which is all easy to use. Visit http://www.dovepress.com/ testimonials.php to read real quotes from published authors. 